\title{
Augmenting the action of levodopa
}

\author{
S. K. RAO \\ M.B., M.R.C.P. (Lond. \& Glas.)
}

S. D. VAKIL

M.B., M.R.C.P.

\author{
D. B. CAlne \\ D.M., M.R.C.P.
}

Department of Medicine, The Royal Postgraduate Medical School and Hammersmith Hospital, London, W.12

A. HILSON
M.B., M.R.C.P.

Department of Neurology, The Royal Free Hospital, London, W.C.1

\begin{abstract}
Summary
Various pharmacological approaches to potentiate the therapeutic actions of levodopa and reduce side-effects are reviewed.

Of currently available drugs, anticholinergic agents and amantadine have been studied extensively. Inhibition of extracerebral decarboxylase appears to be the most promising new area of investigation, though experience is at present limited.

Other methods discussed include inhibition of enzymes catechol-O-methyl transferase, monoamine oxidase and dopamine beta hydroxylase. Conflicting evidence on 3-O-methyldopa is discussed.
\end{abstract}

THERE is severe depletion of dopamine in the brain of Parkinsonian patients (Hornykiewicz, 1966). Levodopa is now a well established treatment for Parkinsonism but its therapeutic action is often associated with prominent unwanted side-effects. Most of the side-effects are dose-dependent.

We review here the various theoretical and practical ways of modifying levodopa treatment in order to minimize side-effects without reduction in therapeutic efficacy.

\section{Anticholinergic drugs}

Before the advent of levodopa therapy for Parkinsonism, anticholinergic drugs were the mainstay of treatment and invariably patients were on one or more of these drugs. It seemed logical to withdraw these when levodopa came to be the effective treatment. Hughes et al. (1971) investigated gradual and sudden withdrawal of anticholinergic drugs in a group of patients receiving a stable dose of levodopa for Parkinsonism. They found that only eleven out of thirty-four patients were able to tolerate either gradual or sudden withdrawal for more than eight weeks. They suggest that synergism seems to exist between anticholinergic drugs and levodopa and this may be due either to inhibition of dopamine inactivation or a primary central anticholinergic effect. Conversely, it would appear from their results that the introduction of anticholinergic drugs in patients treated initially with levodopa is likely to produce additional benefit.

\section{Amantadine}

Amantadine hydrochloride, a drug recently introduced for Parkinsonism (Schwab et al., 1969) has been found to release dopamine and other catecholamines from neuronal storage sites in dogs (Grelak et al., 1970). In mice, the actions of levodopa are potentiated by amantadine (Svensson \& Strömberg, 1970). The reported efficacy of amantadine in Parkinsonism may be due to the release of dopamine, but reports of synergism with levodopa have been conflicting (Godwin-Austen et al., 1970; Hunter et al., 1970a; Parkes et al., 1971; Sacks, Schwartz \& Messeloff, 1971).

\section{Inhibition of catechol-O-methyl transferase}

Catechol-O-methyl transferase (COMT) is an enzyme which contributes to the breakdown of levodopa, dopamine and other monoamine metabolites such as 3,4-dihydroxyphenylacetic acid (DOPAC) and 3,4-dihydroxymandelic acid (DOMA).

If O-methylated derivatives of levodopa and dopamine play any part in producing the adverse effects of levodopa, benefit might come from blocking the action of COMT by suitable inhibitors. Pyrogallol is 
a COMT inhibitor, but it has proved to be too toxic for human use (Braham, 1970). Ericsson (1971) has conducted a clinical trial with $\mathrm{N}$-butylgallate (GPA 1714), a drug which inhibits COMT in vivo and in vitro. He noted alleviation of Parkinsonian features and was able to reduce the dose of levodopa. There was a reduction of nausea, vomiting and involuntary movements.

\section{Inhibition of dopamine beta hydroxylase}

Theoretically, another way to increase the concentration of cerebral dopamine is to block its conversion to noradrenaline by inhibiting the enzyme dopamine beta hydroxylase. In animals disulfiram, a beta hydroxylase inhibitor, was found to increase the concentration of dopamine in the caudate nucleus, hypothalamus and brain stem with a corresponding reduction of noradrenaline (Goldstein \& Nakajima, 1967). Clinically, however, Braham (1970) found no improvement after addition of disulfiram to levodopa therapy.

Fusaric acid, another inhibitor of dopamine beta hydroxylase, has also been investigated in Parkinsonism. When administered in combination with levodopa, a better therapeutic result was achieved than that obtainable with either drug (Hidaka, 1971). Mena, Court \& Cotzias (1971) found that fusaric acid caused neither improvement nor worsening of signs or symptoms of Parkinsonism but they reported that this drug alleviated the involuntary movements produced by levodopa. They suggested that noradrenaline formed from dopamine causes the involuntary movements which occur with levodopa therapy .

\section{Alkalinization of gastric contents}

In six patients who had failed to respond to high doses of levodopa, Rivera-Calimlim et al. (1970) found increased gastric acidity and prolonged emptying time. Fractionation of the gastric juice showed significant quantities of levodopa metabolites, suggesting destruction of administered levodopa in the stomach. Addition of an antacid (magnesium and aluminium hydroxide) resulted in increased levodopa levels in the blood and clinical improvement. An antacid given half an hour before the dose of levodopa may thus prove useful in some patients.

\section{Dopamine agonists}

Apomorphine, a dopaminergic stimulant, is therapeutically active in Parkinsonism and augments the effects of levodopa. However, it causes severe nausea; it has to be injected; and its effects are only brief (Duby, Dahl \& Cotzias, 1971).

\section{Monoamine oxidase inhibitors}

These drugs potentiate the actions of levodopa by blocking the breakdown of dopamine and noradrenaline. Unfortunately, toxic effects are augmented in addition to the therapeutic action (Barbeau, 1961, 1962). Dangerous hypertension has been reported following administration of levodopa with monoamine oxidase inhibitors (Hunter et al., 1970b).

\section{Extracerebral decarboxylase inhibitors}

The most satisfactory method, at present, to potentiate the action of levodopa, is selective blockade of extracerebral decarboxylase as first suggested by Bartholini et al. (1967). Levodopa is avidly decarboxylated to dopamine by the enzyme L-aromatic amino acid decarboxylase in the blood and tissues. Dopamine formed outside the central nervous system does not readily cross the blood-brain barrier. Because L-aromatic amino acid decarboxylase is so widespread, large doses of levodopa must be given to generate a therapeutic blood level. The large intake of levodopa may produce unwanted effects by peripheral adrenergic activity. Drugs are available which inhibit L-aromatic amino acid decarboxylase but are unable to penetrate the blood-brain barrier. The use of extracerebral decarboxylase inhibitors prevents the conversion of levodopa to dopamine in the gut, blood and peripheral tissues, thus enabling a larger proportion of the administered levodopa to cross the blood-brain barrier and there be converted to dopamine.

Initial reports with extracerebral decarboxylase inhibitors, such as L-alpha methyldopahydrazine and seryltrihydroxybenzylhydrazine, are encouraging (Cotzias, Papavasiliou \& Gellene, 1969; Bartholini et al., 1969; Barbeau, 1969; Siegfried et al., 1969; Calne et al., 1971). We now report six patients with idiopathic Parkinsonism, treated with lower doses of $\mathrm{L}$-alpha methyldopahydrazine than have previously been employed.

The patients were treated in a double-blind, randomized cross-over comparison of levodopa with and without L-alpha methyldopahydrazine. Regimen A comprised L-alpha methyldopahydrazine, $100 \mathrm{mg}$ a day in four divided doses, plus maximum tolerated dosage of levodopa. Regimen B comprised levodopa alone in maximum tolerated dosage. Each drug regimen was administered over a period of 6 weeks.

Clinical features were evaluated according to an arbitrary scoring protocol from 0 (normal) to 4 (severe disability). The results are summarized in Table 1. The maximum tolerated doses of levodopa are shown in Table 2. The effects of treatment on nausea (Fig. 1) and blood pressure (Fig. 2) are shown by linked scattergrams.

There were no obvious differences in the therapeutic responses on the two regimens, but nausea was less troublesome when patients were receiving L- 
Augmenting the action of levodopa

TABLE 1. Mean scores for individual therapeutic effects

\begin{tabular}{|c|c|c|c|c|c|c|c|c|c|c|c|c|}
\hline & \multicolumn{2}{|c|}{ Patient 1} & \multicolumn{2}{|c|}{ Patient 2} & \multicolumn{2}{|c|}{ Patient 3} & \multicolumn{2}{|c|}{ Patient 4} & \multicolumn{2}{|c|}{ Patient 5} & \multicolumn{2}{|c|}{ Patient 6} \\
\hline & A & B & A & B & A & B & A & B & A & B & A & B \\
\hline Tremor & $2 \cdot 75$ & $1 \cdot 75$ & 0 & 0 & 1 & 1 & 0 & 0.75 & 0 & 0 & 0 & 0 \\
\hline Rigidity & $1 \cdot 25$ & 0 & 1 & 1 & 0 & 0 & 1 & 1 & 0 & 0 & 0.75 & 1.75 \\
\hline Speech disorder & 0 & 0.25 & 0.5 & 1 & 0 & 0 & 0.5 & 0.5 & 1 & 0.5 & 1 & $1 \cdot 5$ \\
\hline Facial expression & 1 & 0.5 & $2 \cdot 25$ & 2 & 0.75 & $0 \cdot 25$ & 1 & 1 & 2 & $1 \cdot 5$ & $1 \cdot 25$ & 1.75 \\
\hline Arising from chair & 1 & 0.75 & 0.75 & 0.5 & 0 & 0 & 0 & $0 \cdot 25$ & 1 & 0 & 0.75 & 0.75 \\
\hline Balance & 2 & 2 & 0.5 & $0 \cdot 25$ & 0 & 0 & 0.5 & 2 & 2 & 1 & 0.25 & 0 \\
\hline Finger dexterity & $2 \cdot 5$ & 1 & $0 \cdot 25$ & $0 \cdot 25$ & 0 & 0 & 0 & 1 & 2 & $0 \cdot 67$ & 3 & 3 \\
\hline Drooling saliva & 0 & 0 & 2 & 2 & 0 & 0 & 0.5 & 0.25 & 2 & 1.75 & 2 & 2 \\
\hline Sweating & 0.75 & 0.25 & 0.5 & 1 & 0 & 0 & $0 \cdot 25$ & 1 & 1 & 0.75 & 0.25 & 0.75 \\
\hline Gait & 1 & 1 & 0.75 & 0.25 & 0 & 0 & 0 & 0 & 1 & 0 & 1 & 1 \\
\hline Posture & 1 & 1 & 0.75 & 0 & 0 & 0 & 1 & 1 & $\hat{1}$ & 1 & 2 & 2 \\
\hline Dressing & 1 & 1 & 1 & 1 & 0 & 0.5 & 1 & 1 & $2 \cdot 5$ & 3 & 1 & 1.25 \\
\hline Washing & 1 & 1 & 0 & 0.25 & 0 & 0 & 1 & $1 \cdot 5$ & 2 & 2 & 1 & $1 \cdot 25$ \\
\hline Eating & 1 & 1 & 1 & 0.25 & 0 & 0 & 1 & 1 & 2 & 2 & 1 & $1 \cdot 25$ \\
\hline Writing & 2 & $1 \cdot 25$ & 0.25 & $0 \cdot 5$ & 0 & 0 & 1 & 2 & 2 & $3 \cdot 75$ & 1 & 1 \\
\hline \multicolumn{13}{|l|}{ Timed tests (sec) } \\
\hline Paper folding & 5.62 & 4.85 & 11.67 & 10.12 & 9.2 & $10 \cdot 2^{*}$ & 8.3 & $10 \dagger$ & \multicolumn{2}{|c|}{ Patient } & 13.3 & 14.3 \\
\hline Peg test & 7.25 & 8.6 & $10 \cdot 27$ & 8.67 & 12.8 & $11.5^{*}$ & 13.3 & $13.1 \ddagger$ & \multicolumn{2}{|c|}{ too } & 9.9 & 14.4 \\
\hline Walking & 33.62 & 28.27 & 20.67 & 20.07 & 15.7 & $14.4^{*}$ & 15 & $14 \dagger^{\top}$ & \multicolumn{2}{|c|}{ confused } & 17 & 17.5 \\
\hline Writing & 26.4 & 22.97 & 16.85 & 17.1 & 17.1 & $17.3^{*}$ & 14.2 & $15 \ddagger$ & \multicolumn{2}{|c|}{ to assess } & $18.7^{*}$ & 22 \\
\hline
\end{tabular}

$A$ and $B$, regimens

* Mean of three assessments

$\dagger$ Mean of two assessments

$\ddagger$ On one occasion only

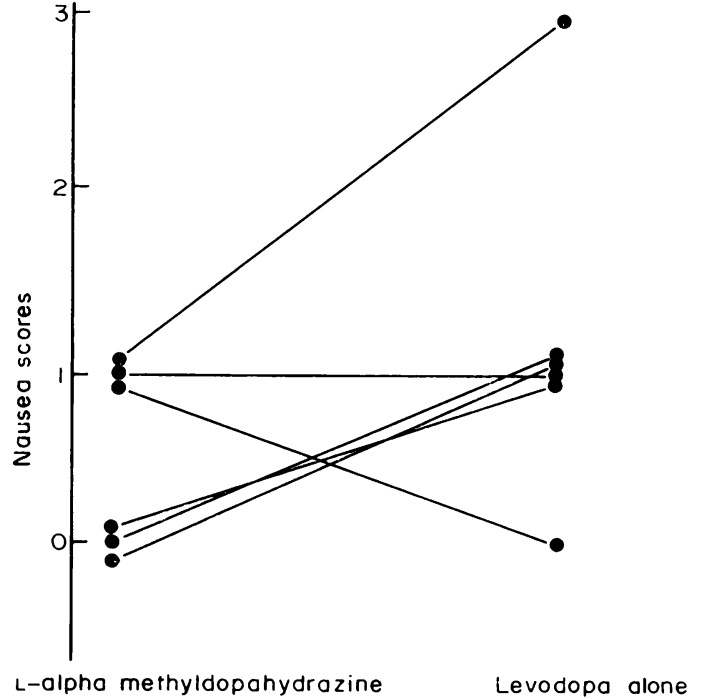

+ levodopo

FIG. 1. Nausea scores on each regimen.

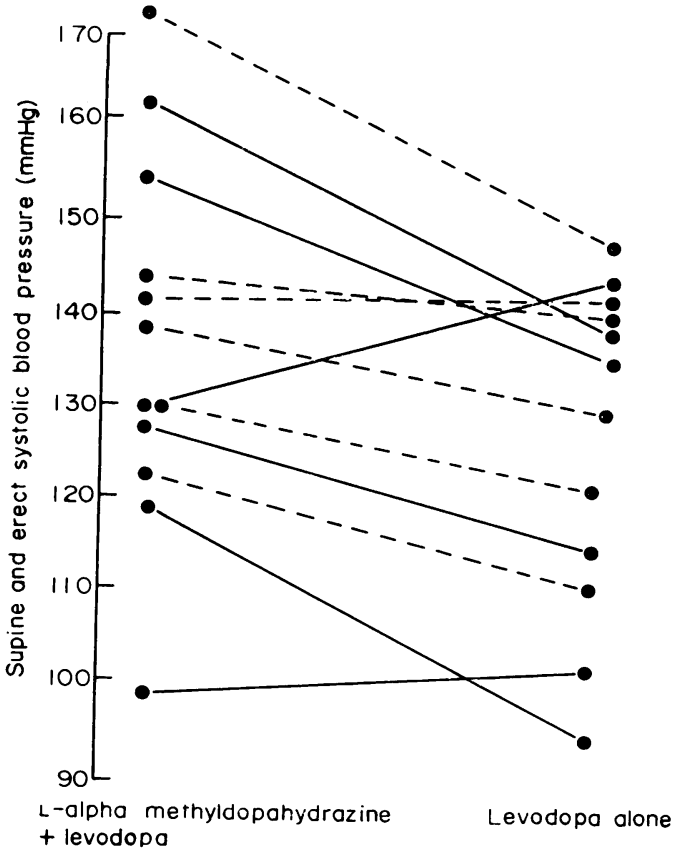

FIG. 2. Blood pressures on each regimen. -..., supine; 
TABLE 2. Mean maximum tolerated doses of levodopa (g)

\begin{tabular}{ccc}
\hline Patient & Regimen A & Regimen B \\
\hline 1 & $0 \cdot 15$ & $0 \cdot 18$ \\
2 & $0 \cdot 3$ & $1 \cdot 93$ \\
3 & $0 \cdot 35$ & 3 \\
4 & $0 \cdot 3$ & $2 \cdot 6$ \\
5 & $0 \cdot 35$ & 2 \\
6 & $0 \cdot 45$ & 4 \\
Means & $0 \cdot 32$ & $2 \cdot 4$ \\
\hline
\end{tabular}

alpha methyldopahydrazine. By elevating the blood pressure slightly, inhibition of extracerebral decarboxylase militated against the mild hypotension commonly induced by levodopa. Although similar therapeutic effects were achieved on each regimen, the dose of levodopa was substantially lower when given in combination with L-alpha methyldopahydrazine.

The overall results are very similar to those obtained with three times the dose of L-alpha methyldopahydrazine (Calne et al., 1971).

\section{Acknowledgments}

We thank Gillian Bance for help with the tables, Carol Moore for secretarial assistance and Merck Sharp \& Dohme Ltd for generous supplies of levodopa and L-alpha methyldopahydrazine (MK-486).

\section{References}

BARBEAU, A. (1961) Abstracts of papers. Seventh International Congress of Neurology, Excerpta Medica Foundation, Amsterdam.

BARBEAU, A. (1962) The pathogenesis of Parkinson's disease: A new hypothesis. Canadian Medical Association Journal, $87,802$.

Barbeau, A. (1969) L-dopa therapy in Parkinson's disease. Canadian Medical Association Journal, 101, 791.

Bartholini, G., Burkard, W.P., Pletscher, A. \& Bates, H.M. (1967) Increase of cerebral catecholamines caused by 3, 4-dihydroxyphenylalanine after inhibition of peripheral decarboxylase. Nature, 215, 852.

Bartholini, G., Tissot, R. \& Pletscher, A. (1969) Third Symposium on Parkinson's Disease (Ed. by F. J. Gillingham and I. M. L. Donaldson), p.192. Livingstone, Edinburgh.

Braham, J. (1970) Adjuvants to L-dopa for Parkinsonism. British Medical Journal, 3, 540.

Calne, D.B., Reid, J.L., Vakil, S.D., Rao, S., Petrie, A., Pallis, C.A., Gawler, J., Thomas, P.K. \& Hilson, A. (1971a) Idiopathic Parkinsonism treated with an extracerebral decarboxylase inhibitor in combination with levodopa. British Medical Journal, 3, 729.

Calne, D.B., Reid, J.L., Vakil, S.D., Rao, S., Pallis, C.A., Thomas, P.K. \& Hilson, A. (1971b) Extracerebral decarboxylase inhibition in Parkinsonism. Proceedings of Asian and Oceanic Congress of Neurology, Bombay (in press).

Calne, D.B., Petrie, A., Rao, S., Reid, J.L., \& Vakil, S.D. (1972) Action of L-alpha methyldopahydrazine on the blood pressure of patients receiving levodopa. British Journal of Pharmacology, 44, 162.
Cotzias, G.C., Papavasiliou, P.S. \& Gellene, R. (1969) Modification of Parkinsonism-chronic treatment with L-dopa. New England Journal of Medicine, 280, 337.

Duby, S.E., Dahl, L.K. \& Cotzias, G.C. (1971) Coupling of hypotensive and anti-Parkinson effects with two dopaminergic drugs. Clinical Research, 19, 577.

ERICSSON, A.L. (1971) Potentiation of the L-dopa effect in man by the use of catechol-O-methyltransferase inhibitors. Journal of the Neurological Sciences, 14, 193.

Godwin-Austen, R.B., Frears, C.C., Bergmann, S., PARKes, J.D. \& KNILl-Jones, R.P. (1970) Combined treatment of Parkinsonism with L-dopa and amantadine. Lancet, ii, 383.

Goldstein, M. \& Nakajima, K. (1967) The effect of disulfiram on catecholamine levels in the brain. Journal of Pharmacology and Experimental Therapeutics, 157, 96.

Grelak, R.P., Clark, R., Stump, J.M. \& Vernier, V.G. (1970) Amantadine-dopamine interaction: possible mode of action in Parkinsonism. Science, 169, 103.

HidAKA, H. (1971) Fusaric (5-butylpicolinic) acid, an inhibitor of dopamine beta hydroxylase, affects serotonin and noradrenaline. Nature, 231, 54.

HoRNYKIEWICZ, O. (1966) Dopamine (3 hydroxytyramine) and brain function. Pharmacological Reviews, 18, 925.

Hughes, R.C., Polgar, J.G., Weightman, D. \& Walton, J.N. (1971) Levodopa in Parkinsonism: the effects of withdrawal of anticholinergic drugs. British Medical Journal, 2 487.

Hunter, K.R., Stern, G.M., Laurence, D.R., \& Armitage P. (1970a) Combined treatment of Parkinsonism with L-dopa and amantadine. Lancet, ii, 566.

Hunter, K.R., Boakes, A.J., Laurence, D.R. \& Stern, G.M. (1970b) Monoamine oxidase inhibitors and L-dopa. British Medical Journal, 3, 388.

Mena, I., Court, J. \& Cotzias, C. (1971) Levodopa, involuntary movements and fusaric acid. Journal of the American Medical Association, 218, 1829.

Parkes, J.D., Zilkha, K.J., Marsden, P., Baxter, R.C.H. \& KNill-Jones, R.P. (1970) Amantadine dosage in treatment of Parkinson's disease. Lancet, i, 1130.

Reid, J.L., Calne, D.B., Rao, S., George, C.F., Vakil, S.D. \& Pallis, C.A. (1971c) Hypotension induced by levodopa. Proceedings of Asian and Oceanic Congress of Neurology, Bombay (in press).

Rivera-Calimlim, L., Dujovne, C.A., Morgan, J.P., LASAGNA, L. \& BiANCHINE, J.R. (1970) L-dopa treatment failure: Explanation and correction. British Medical Journal, 4, 93.

SaCKs, O., Schwartz, W.F. \& Messeloff, C.R. (1971) Interactions of L-dopa and amantadine in Parkinsonism. Clinical Pharmacology and Therapeutics, 12, 301.

Sandler, M., Goodwin, B.L., Ruthven, C.R.J., \& Calne D.B. (1971) Therapeutic implications in Parkinsonism of m-tyramine formation from L-dopa in man. Nature, 229, 414.

Schwab, R.S., England, A.C., Poskanzes, D.C. \& Young, R.R. (1969) Amantadine in the treatment of Parkinson's disease. Journal of the American Medical Association, 208, 1168.

Siegfried, J., Zeigler, W.H., Regli, F., Fischer, C., KaufmanN, W. \& Perret, E. (1969) Treatment of Parkinsonism with L-dopa in association with a dacarboxylase inhibitor. First objective results. Pharmacologia Clinica, 2, 23.

Svensson, T.H. \& Strömberg, U. (1970) Potentiation by amantadine hydrochloride of L-dopa-induced effects in mice. Journal of Pharmacy and Pharmacology, 22, 639. 